\title{
Tonsillectomy rates in the South African private healthcare sector
}

\author{
P Douglas-Jones, MB ChB; J J Fagan, MB ChB, MMed, FCORL \\ Division of Otorhinolaryngology, Faculty of Health Sciences, University of Cape Town, South Africa
}

Corresponding author: P Douglas-Jones (pdouglasjones@gmail.com)

\begin{abstract}
Background. Adeno-/tonsillectomy is a commonly performed procedure with internationally standardised and recognised indications. Despite this, there exists considerable international (190 - 850/100 000 people $\leq 19$ years of age) and regional variation in rates. This cannot be accounted for by differences in clinical need or regional morbidity.

Objectives. To describe the adeno-/tonsillectomy rate in the South African (SA) private healthcare sector and regional variations thereof. To compare local rates with international rates and assess trends in adeno-/tonsillectomy practice.

Methods. Analysis of 2012 and 2013 adeno-/tonsillectomy data provided by the largest SA private healthcare funder, accounting for 30\% of the medical scheme market. Rates are expressed per 100000 people $\leq 19$ years of age.

Results. The tonsillectomy rate in the SA private healthcare sector was $1888 / 100000$ people $\leq 19$ years of age in 2012. In 2013, the rate dropped significantly $(p<0.001)$ to $1755 / 100000$. This is more than double the highest national tonsillectomy rate reported in the literature. There was also considerable regional variation in this rate within SA.

Discussion. The SA tonsillectomy rate is very high when compared with international trends and varies regionally within the country. The literature does not support an increased burden of disease as the reason behind this. Rather, it is differences in training and clinical practice of clinicians, as well as social and family factors, that have been implicated.

Conclusion. The adeno-/tonsillectomy rate in the SA private healthcare sector is substantially higher than international norms. The reasons for this discrepancy require further consideration.
\end{abstract}

S Afr Med J 2016;106(11):1134-1140. DOI:10.7196/SAMJ.2016.v106i11.10842

Tonsillectomy, performed with or without adenoidectomy, is one of the most frequently performed surgical procedures in children. ${ }^{[1,2]}$ In the USA, tonsillectomy accounts for one-third of the paediatric procedures performed under general anaesthesia. ${ }^{[3]}$ It is, however, a procedure that lacks evidence of being clinically effective ${ }^{[4]}$ and cost-effective. ${ }^{[5]}$ It is interesting to note a steady decline in the US tonsillectomy rate in recent times, ${ }^{[1]}$ as evidence in support of the procedure has been found to be equivocal. A similar trend is evident in the UK, with only a quarter the number of tonsillectomies performed in the modern era compared with the early 20 th century. ${ }^{[6]}$

The two major indications for tonsillectomy are recurrent throat infections and sleep disordered breathing (SDB), both of which can impact significantly on general health and quality of life. ${ }^{[7]}$ In the 1980 s, $80 \%$ of tonsillectomies were performed for infective indications i.e. recurrent tonsillitis or sore throat. ${ }^{[7]}$ There has, however, been a shift in clinical practice in recent years. In 2011, $85 \%$ of tonsillectomies were performed for obstructive symptoms i.e. SDB. ${ }^{[8]}$ Despite wellestablished, evidence-based guidelines having been published by various groups (Table 1), the indications for tonsillectomy remain controversial and have been a source of much debate among the role players managing these patients. ${ }^{[9]}$ It is surprising to note, therefore, that for such a common procedure with internationally recognised and standardised indications, there exists significant international variation in tonsillectomy rates. Furthermore, tonsillectomy rates show considerable regional/geographical variation within the same country. This variation has been ascribed to differences in clinical practice and referral patterns, as well as social ${ }^{[10]}$ and family factors, ${ }^{[11]}$ rather than differences in clinical need or regional morbidity. ${ }^{[12-14]}$

Between 2000 and 2005, Suleman et al. ${ }^{[15]}$ reported a national annual tonsillectomy rate of 304/100 000 children $<15$ years of age for the National Health Service (NHS) in England. Interestingly, tonsillectomy rates varied sevenfold across local authority areas. This substantial variation was even greater when tonsillectomy data from the independent healthcare sector (representing 15\% of ear, nose and throat activity in the UK) were factored into the calculations. In Scotland in 1992, regional tonsillectomy rates showed a threefold variation. ${ }^{[16]}$

In the USA, Boss et al. ${ }^{[1]}$ described a tonsillectomy rate of $791 / 100000$ children $\leq 19$ years of age in 2012, with a fourfold regional variation in rate. Tonsillectomy rates in children insured by the state-funded Medicaid programme in the USA were similar to those insured by private sources.

In Germany, the annual average adeno-/tonsillectomy rate between 2007 and 2010 was reported as $480 / 100000$ for children and adolescents $\leq 19$ years of age. ${ }^{[17]}$ The tonsillectomy rate varied up to threefold among German federal states. There was an even greater variation when tonsillectomy rates were analysed at a district level, with rates in some districts up to eight times higher than in other districts.

The lowest national tonsillectomy rate reported in the literature is that of Canada, with a rate of $190 / 100000$ children $\leq 19$ years of age. Northern Ireland has the highest reported rate, 850/100 000 . Other countries for which the national tonsillectomy rate has been calculated include Finland (605/100 000), Australia (620/100 000), Belgium (685/100 000) and the Netherlands (790/100 000). ${ }^{[18]}$

The South African (SA) adeno-/tonsillectomy rate has never been described before. It has therefore been difficult to compare local practice with international norms. Describing the adeno- $/$ tonsillectomy rate is a daunting task because of the complexity of the SA healthcare system, which comprises both public and private sectors. In 2013, the private healthcare sector catered for the $18 \%$ of the population $(9.7 \text { million people })^{[19]}$ who could afford the 
Table 1. Indications for adeno-/tonsillectomy ${ }^{[1,2,21,24]}$

\begin{tabular}{|c|c|c|c|}
\hline & Paradise criteria & $\begin{array}{l}\text { Scottish Intercollegiate } \\
\text { Guideline }\end{array}$ & $\begin{array}{l}\text { American Academy of Otolaryngo- } \\
\text { logy - Head and Neck Surgery }\end{array}$ \\
\hline $\begin{array}{l}\text { Frequency of throat } \\
\text { infections }\end{array}$ & $\begin{array}{l}\geq 7 \text { in preceding year } \\
\text { OR } \\
\geq 5 \text { per year in preceding } 2 \text { years } \\
\text { OR } \\
\geq 3 \text { per year in preceding } 3 \text { years }\end{array}$ & $\begin{array}{l}\geq 7 \text { in preceding year } \\
\text { OR } \\
\geq 5 \text { per year in preceding } 2 \text { years } \\
\text { OR } \\
\geq 3 \text { per year in preceding } 3 \text { years }\end{array}$ & $\begin{array}{l}\geq 7 \text { in preceding year } \\
\text { OR } \\
\geq 5 \text { per year in preceding } 2 \text { years } \\
\text { OR } \\
\geq 3 \text { per year in preceding } 3 \text { years }\end{array}$ \\
\hline Clinical features & $\begin{array}{l}\text { In addition to sore throat, one or } \\
\text { more of the following: } \\
\text { Temperature }>38.3^{\circ} \mathrm{C} \\
\text { OR } \\
\text { Cervical lymphadenopathy } \\
\text { (tender or }>2 \mathrm{~cm} \text { ) } \\
\text { OR } \\
\text { Tonsillar exudate } \\
\text { OR } \\
\text { Culture positive for group A } \\
\beta \text {-haemolytic streptococcus }\end{array}$ & & $\begin{array}{l}\text { In addition to sore throat, one or more } \\
\text { of the following: } \\
\text { Temperature }>38.3^{\circ} \mathrm{C} \\
\text { OR } \\
\text { Cervical lymphadenopathy (tender or } \\
>2 \mathrm{~cm} \text { ) } \\
\text { OR } \\
\text { Tonsillar exudate } \\
\text { OR } \\
\text { Culture positive for group A } \\
\beta \text {-haemolytic streptococcus }\end{array}$ \\
\hline $\begin{array}{l}\text { Modifying factors: } \\
\text { Favouring tonsillectomy if } \\
\text { frequency criteria not met }\end{array}$ & & & $\begin{array}{l}\text { Multiple antibiotic allergy/intolerance } \\
\text { History of peritonsillar abscess } \\
\text { PFAPA (periodic fever, } \\
\text { aphthous stomatitis, } \\
\text { pharyngitis and adenitis) }\end{array}$ \\
\hline Antibiotics & $\begin{array}{l}\text { Administered in conventional } \\
\text { dose for suspected/proven } \\
\text { streptococcal episodes }\end{array}$ & & \\
\hline Documentation & $\begin{array}{l}\text { Each episode and associated } \\
\text { clinical features recorded }\end{array}$ & $\begin{array}{l}\text { Episodes should be well } \\
\text { documented }\end{array}$ & $\begin{array}{l}\text { Each episode and associated clinical } \\
\text { and social features recorded }\end{array}$ \\
\hline $\begin{array}{l}\text { SDB/ } \\
\text { polysomnography }\end{array}$ & & & $\begin{array}{l}\text { Counsel caregivers about } \\
\text { tonsillectomy as a means to improve } \\
\text { health in children with abnormal } \\
\text { polysomnography } \\
\text { Ask about comorbid conditions that } \\
\text { might improve with tonsillectomy: } \\
\text { growth retardation, poor school } \\
\text { performance, enuresis, behavioural } \\
\text { problems }\end{array}$ \\
\hline Watchful waiting & $\begin{array}{l}\text { Observe for } 12 \text { months, owing to } \\
\text { tendency of throat infections to } \\
\text { improve over time }\end{array}$ & & \\
\hline
\end{tabular}

monthly premiums or those who were willing to pay a fee for private healthcare. This audit focused on the private healthcare sector and excluded the resource-constrained public healthcare sector, as adeno-/ tonsillectomy in the state sector is generally reserved for children with severe SDB, owing to poor access to healthcare and specialist services. The public sector serves $82 \%$ of the population ( 43.4 million people) and is heavily burdened, with facilities overcrowded, underfunded and understaffed. Uninsured SA patients therefore have limited access to tonsillectomy at state hospitals, where the indications for such surgical procedures are often modified to be locally relevant and ensure sustainable service provision.

It has long been accepted that tonsillectomy in children suffering from recurrent throat infections improves quality of life, reduces the number of visits to healthcare providers and reduces antibiotic use. ${ }^{[20]}$ However, evidence supporting surgery for infective/sore throat indications is equivocal. Most trials investigating efficacy of the procedure ${ }^{[21-23]}$ display bias due to poorly defined entrance criteria, non-randomised selection of cases, exclusion of the most severely affected patients and reliance on caregivers for data collection. In a 2014 Cochrane review ${ }^{[4]}$ assessing the effectiveness of adeno-/ tonsillectomy in reducing the frequency and severity of sore throat in patients with chronic or recurrent acute tonsillitis, benefit was shown to be modest at best. When compared with non-surgical management, operated patients experienced only 1.4 fewer episodes of sore throat in the first year postoperatively, at the cost of one sore throat as a consequence of surgery. It was also noted that children with the most severe symptoms were most likely to experience benefit from surgical management and that some children's symptoms resolved without any 
surgery. No firm conclusions could be reached on the effectiveness of surgical as opposed to non-surgical management as there was insufficient information available.

Adeno-/tonsillectomy is, therefore, a procedure in search of evidence.

\section{Objectives}

The SA tonsillectomy rate has, to the authors' knowledge, never been reported. This audit set out to describe the tonsillectomy rate in the SA private healthcare sector, which compares favourably with health systems in the developed world and countries in which tonsillectomy rates have been reported. The objective was to define both national and regional adeno-/tonsillectomy rates. Determining the tonsillectomy rate in the SA private healthcare sector would provide a tool enabling comparisons of SA practice with international trends. It would also aid in justifying recommendations regarding the modification of local tonsillectomy indications, to align SA practice with internationally accepted norms. This audit also set out to identify and comment on trends in clinical practice with regard to adeno-/tonsillectomy in the SA private healthcare sector.

\section{Methods}

A retrospective review of the 2012 and 2013 adeno-/tonsillectomy data from Discovery Health Medical Scheme, SA's largest private healthcare insurer, was performed. Of the $18 \%$ (9.7 million people) of South Africans with private medical insurance, Discovery Health Medical Scheme accounts for a 30\% (approximately 2.7 million people) market share. Of this sample, 771720 people in 2012 and 797310 people in 2013 were 19 years of age or younger. This cohort comprised the study population. This correlates with most international studies, where the national tonsillectomy rate has been calculated for this age group. Using STATA 12.0 (StataCorp, USA) data analysis and statistical software, we calculated the SA tonsillectomy rate per 100000 people $\leq 19$ years of age and compared this rate with international rates reported in the literature. The regional tonsillectomy rate was also calculated for 16 geographical regions defined by Discovery Health. The $95 \%$ confidence intervals (CIs) were calculated for both the national and regional tonsillectomy rates. We also calculated the percentage of adeno-/tonsillectomies performed by ear, nose and throat (ENT) surgeons and the percentage performed by GPs, as well as the ENT surgeon-to-patient ratio, both nationally and regionally.

Adeno-/tonsillectomy data for the same period were also sourced from Bonitas Medical Fund, another of SA's large private medical aid providers. Bonitas insures 7\% of privately insured South Africans, roughly 650000 people in 2013. Of this sample, 204842 people in 2012 and 228429 people in 2013 were 19 years of age or younger. The national adeno-/tonsillectomy rate within the Bonitas-insured population was calculated and compared with the Discovery Medical Scheme rate.

\section{Results}

Within the Discovery Health Medical Scheme cohort, a total of 14574 and 13989 adeno-/tonsillectomies were performed in 2012 and 2013, respectively. The SA private healthcare sector adeno-/ tonsillectomy rate in 2012 was $1888 / 100000$ people $\leq 19$ years of age. The rate dropped significantly to $1755 / 100000$ in $2013(p<0.001)$. Both are more than double the highest tonsillectomy rate reported in the literature. There was also considerable regional variation in the adeno-/tonsillectomy rate within SA ( $p=0.046$; pooled 2-year data). In 2012 and 2013, the highest regional rate was observed in the West Coast/Karoo/Cape Town Northern Suburbs region: $2754 / 100000$ and $2507 / 100000$ people $\leq 19$ years of age, respectively. The lowest adeno-tonsillectomy rate was reported in Polokwane in 2012 (1307/100 000) and East London in 2013 (1 445/100 000). From 2012 to 2013, four regions demonstrated an increase in adeno- $/$ tonsillectomy rate: the Overberg, the Garden Route, East London and Polokwane. This goes against the national reduction in rate observed over the same period. Results are summarised in Table 2.

GPs performed 2726 of the 13989 adeno-/tonsillectomies in 2013, i.e. about $20 \%$. Otorhinolaryngologists operated on the remaining 11263 patients, i.e. $80 \%$ of adeno-/tonsillectomies performed in

Table 2. Regional variation in the SA adeno-/tonsillectomy rate/100 000 for Discovery-insured population $\leq 19$ years of age

\begin{tabular}{|c|c|c|c|}
\hline Region & $\begin{array}{l}\text { Tonsillectomy rate } \\
2012(95 \% \text { CI })\end{array}$ & $\begin{array}{l}\text { Tonsillectomy rate } \\
2013(95 \% \text { CI })\end{array}$ & $\begin{array}{l}\text { Average rates } \\
2012 / 2013\end{array}$ \\
\hline Polokwane & $1307(1123-1513)$ & $1473(1281-1688)$ & 1390 \\
\hline East London & $1400(1220$ - 1597$)$ & $1445(1265-1642)$ & 1423 \\
\hline Durban & $1516(1439-1596)$ & $1459(1384-1535)$ & 1488 \\
\hline Port Elizabeth & $1569(1411-1739)$ & $1468(1316-1632)$ & 1519 \\
\hline Johannesburg & $1668(1620-1717)$ & $1530(1485-1577)$ & 1599 \\
\hline Cape Town Peninsula & $1694(1579-1815)$ & $1592(1482-1708)$ & 1643 \\
\hline Pietermaritzburg & $1822(1626-2037)$ & $1555(1375-1752)$ & 1689 \\
\hline Nelspruit & $1794(1558-2055)$ & $1659(1434-1908)$ & 1727 \\
\hline Rustenburg & $1902(1668-2160)$ & $1701(1484-1945)$ & 1802 \\
\hline Overberg & $1852(1634-2091)$ & $2075(1848-2323)$ & 1964 \\
\hline Pretoria & $2218(2132-2305)$ & 1969 (1 890 - 2045$)$ & 2094 \\
\hline Vaal Triangle & $2250(2000-2522)$ & $2241(1998-2506)$ & 2246 \\
\hline Garden Route & $2198(1926-2488)$ & $2348(2069-2655)$ & 2273 \\
\hline Potchefstroom & $2460(2197-2746)$ & 2268 (2 019 - 2 539) & 2364 \\
\hline Bloemfontein ${ }^{\star}$ & $2586(2402-2781)$ & $2404(2230-2589)$ & 2495 \\
\hline West Coast/Karoo ${ }^{\dagger}$ & $2753(2629-2882)$ & $2507(2391-2628)$ & 2630 \\
\hline SA overall ${ }^{\ddagger}$ & 1888 (1 858 - 1919$)$ & $1755(1726-1784)$ & 1820 \\
\hline
\end{tabular}


2013 were performed by ENT surgeons $(p<0.001)$. The percentage of adeno-/tonsillectomies performed by otorhinolaryngologists varied widely from region to region. In the Overberg, otorhinolaryngologists performed more than $99 \%$ of procedures. However, in the Vaal triangle, otorhinolaryngologists performed only $28 \%$ of adeno-/ tonsillectomies.

There did not appear to be any correlation between regional tonsillectomy rate and proportion of tonsillectomies performed by otorhinolaryngologists as opposed to GPs. In the three regions with the highest adeno-/tonsillectomy rates, Potchefstroom, Bloemfontein and the West Coast/Karoo, otorhinolaryngologists performed 53\%, $75 \%$ and $91 \%$ of procedures, respectively. Similarly, in the three regions with the lowest adeno-/tonsillectomy rates, Polokwane, East London and Durban, otorhinolaryngologists performed 41\%, $91 \%$ and $88 \%$ of procedures. As such, regional tonsillectomy rates seem to reflect local practice preferences, rather than surgeon qualification.

Also noted was that the ENT surgeon-to-patient ( $\leq 19$ years of age) ratio ranged from 1:1 809 along the Garden Route, to 1:4 889 in Johannesburg. Once again, there was poor correlation between regional ENT surgeon-to-patient ratio and regional adeno- $/$ tonsillectomy rate. In the three regions with the highest adeno- $/$ tonsillectomy rates, ENT surgeon-to-patient ratio ranged from 1:2 666 in Bloemfontein (the fourth-lowest ratio in SA) to 1:4 424 in Potchefstroom (the third-highest ratio in SA). These findings are summarised in Table 3.

The national adeno-/tonsillectomy rate calculated in the Bonitasinsured population was $1164 / 100000$ people $\leq 19$ years of age in 2012 (95\% CI 1118 - 1 212) and 1 166/100 000 in 2013 (95\% CI 1121 $1211)$. This rate is lower than the rate calculated in the Discoveryinsured population, but still significantly higher than international norms. The finding of an elevated tonsillectomy rate in the SA private healthcare sector is therefore not limited to the Discovery-insured population, but reproducible by at least one other insurer, suggesting a market trend.

\section{Discussion}

The SA tonsillectomy rate in the private healthcare sector (Discovery Medical Scheme-insured population) is significantly higher than that reported in the literature in other countries. It is roughly 10 times the rate described in Canada and more than double the highest reported rate, that of Northern Ireland. This finding was not limited to a single medical aid provider. The Bonitas adeno-/tonsillectomy rate was roughly six times higher than the Canadian rate. There is also significant regional variation in the adeno-/tonsillectomy rates within SA.

These findings raise an important question: What causes international and regional variation in adeno-/tonsillectomy rates and why is the SA rate the highest in the literature? Contributing factors are discussed below.

\section{Differences in training}

Differences in postgraduate training of otorhinolaryngology registrars have been shown to influence surgical practice and regional tonsillectomy rates. ${ }^{[24]}$ In addition, Bloor et al. ${ }^{[25]}$ noted that the otorhinolaryngologist attitude towards tonsillectomy was partly responsible for regional variation. The Paradise criteria are applied at the authors' institution. Allowance is, however, made for deviation from the guidelines at the clinician's discretion, if it is deemed reasonable, rational and in the best interests of the patient. Similarly, all otorhinolaryngology training units in SA apply the Paradise Criteria, the guidelines devised by the Scottish Intercollegiate Guidelines Network (SIGN) or the American Academy of Otolaryngology - Head and Neck Surgery (AAO-HNS) Clinical Practice Guidelines, occasionally with minor variations thereof.

\section{Lack of consensus among role players managing} throat infections/SDB

Capper and Canter ${ }^{[26]}$ found that among those managing tonsillitis and SDB, GPs, otorhinolaryngologists and paediatricians failed to agree on

Table 3. Regional breakdown of the number of general practitioners and ENT surgeons performing adeno-/tonsillectomies in 2013, and the regional division of labour

\begin{tabular}{|c|c|c|c|c|}
\hline Region & $\begin{array}{l}\text { GPs performing adeno-/ } \\
\text { tonsillectomy, } n\end{array}$ & $\begin{array}{l}\text { ENT surgeons performing } \\
\text { adeno-/tonsillectomy, } n\end{array}$ & $\begin{array}{l}\text { ENT surgeon-to-patient } \\
\text { ratio ( } \leq 19 \text { years of age) }\end{array}$ & $\begin{array}{l}\text { Percentage of adeno-/ } \\
\text { tonsillectomies } \\
\text { performed by ENT } \\
\text { surgeon (\%) }\end{array}$ \\
\hline Bloemfontein ${ }^{\star}$ & 51 & 11 & $1: 2666$ & 75 \\
\hline Cape Town Peninsula & 12 & 15 & $1: 3245$ & 97 \\
\hline Durban & 36 & 27 & $1: 3652$ & 88 \\
\hline East London & 5 & 5 & $1: 3240$ & 91 \\
\hline Garden Route & 6 & 6 & $1: 1809$ & 91 \\
\hline Johannesburg & 104 & 58 & $1: 4889$ & 76 \\
\hline Nelspruit & 3 & 3 & $1: 3919$ & 96 \\
\hline Overberg & 1 & 6 & $1: 2426$ & 99 \\
\hline Pietermaritzburg & 13 & 9 & 1:1930 & 47 \\
\hline Polokwane & 21 & 3 & $1: 4775$ & 41 \\
\hline Port Elizabeth & 23 & 7 & 1:3 309 & 53 \\
\hline Potchefstroom & 34 & 3 & $1: 4424$ & 53 \\
\hline Pretoria & 97 & 41 & $1: 2919$ & 88 \\
\hline Rustenburg & 10 & 3 & $1: 4249$ & 63 \\
\hline Vaal Triangle & 31 & 5 & $1: 2749$ & 28 \\
\hline West Coast/Karoo ${ }^{\dagger}$ & 29 & 24 & $1: 2897$ & 91 \\
\hline SA overall & 476 & 226 & $1: 3528$ & 80 \\
\hline
\end{tabular}


the diagnostic features of tonsillitis, pharyngitis and upper respiratory tract infections. There was also professional disagreement on the indications for tonsillectomy among the groups and a statistically significant difference in perceived benefit of the procedure and expectations regarding the postoperative improvement in symptoms (frequency of sore throats, irregular breathing, irritability and poor concentration). As ENT surgeons are unlikely to be managing patients suffering from acute episodes of throat infection/sore throat, they rely on primary healthcare providers/GPs to provide them with as much information as possible to make an evidence-based decision on whether adeno-/tonsillectomy is indicated and likely to be of benefit. This includes information such as frequency of throat infections, associated clinical factors and socioeconomic as well as family impact of the disease. Tucker ${ }^{[27]}$ highlights that even among otorhinolaryngologists, there is disagreement about the significance of the signs and symptoms in children with recurrent tonsillitis. It therefore appears that there is no clear management protocol for children suffering from recurrent tonsillitis and SDB. This generalised lack of consensus is concerning and efficient patient care can only be provided if all role players, reliant on one another in managing these children, are in agreement.

\section{Variation in the implementation of evidence-based guidelines}

Although studies since the 1970s have defined a suitable candidate population, many clinicians are still uncertain as to the indications for tonsillectomy. ${ }^{[28]}$ In certain instances, only $35 \%$ of patients undergoing adeno-/tonsillectomy have been shown to meet the published criteria. ${ }^{[29]}$ Even more concerning is Marshall et al.'s ${ }^{[30]}$ finding that only a quarter of patients undergoing tonsillectomy for recurrent throat infection met evidence-based criteria. Despite this, the Scottish tonsillectomy audit notes that between $63.3 \%$ and $89.8 \%$ of patients referred to ENT surgeons because of recurrent tonsillitis, sore throat or obstructive symptoms are booked for tonsillectomy on their first visit to an outpatient ENT clinic. ${ }^{[16]}$ This suggests that ENT surgeons are generally liberal when promoting tonsillectomy as a therapeutic option and often forego a period of watchful waiting, despite the recommendation of the guidelines to observe patients for a period of at least 6 months. Evidence also points to the fact that surgeons are more likely to break existing guidelines in favour of performing surgery rather than withholding surgery. ${ }^{[31]}$

When tonsillectomy is considered for SDB, overnight polysomnography is the gold standard in confirming the diagnosis and making recommendations with regard to management. The American Academy of Paediatrics advises polysomnography in all children suspected of experiencing SDB, prior to surgical intervention. ${ }^{[32]}$ Others feel that it is not necessary to request polysomnography this liberally, as it gives no insight into the effect of the sleep disorder on the patient's general wellbeing. Otorhinolaryngologists request polysomnography in less than $10 \%$ of children undergoing adeno-/ tonsillectomy. ${ }^{[33]}$

Although protocol-driven healthcare has its place in modern medicine, the authors of this study agree that it is ill-advised to implement guidelines blindly, at the expense of doctor insight, acumen and experience. The other extreme would be to flout guidelines entirely and enable doctors to operate on patients at their discretion. Whether or not this could be regarded as reasonable practice is debatable and beyond the scope of this article.

\section{Inconclusive evidence on the effectiveness and benefit of adeno-/tonsillectomy}

In their landmark trials conducted in Pittsburgh in 1984 and 2002, Paradise et al..$^{[21,23]}$ set out to determine the efficacy of adeno-/ tonsillectomy in reducing the number and severity of subsequent throat infections. In their initial study, eligibility required children to satisfy the 'Paradise criteria.' They noted that tonsillectomy is efficacious in reducing the number and severity of throat infections for 2 years, and possibly a third year, following surgery. The study concluded that the degree of benefit experienced justified tonsillectomy in those meeting the strict inclusion criteria, but also emphasised that many children treated non-surgically improved spontaneously. The benefit seems modest as best. In the follow-up study, the Paradise criteria were relaxed somewhat to evaluate whether or not tonsillectomy would afford equivalent benefit to those children less severely affected than those in the previous trial. The study concludes that the limited benefit conferred by tonsillectomy in moderately affected children is outweighed by the risk, morbidity and cost of the surgery. In both studies, the mean number of days of sore throat in the 12 months following surgery was not statistically different between the operated and the non-operated group. Other studies reported that in children on waiting lists for adeno-/tonsillectomy, 18.6 - 50\% of individuals no longer required surgery with a follow-up period of up to 3 years. ${ }^{[34-38]}$ This points towards the understanding that there is a spontaneous reduction in rates of recurrent infection over time.

A 2006 literature review ${ }^{[39]}$ suggested that adeno-/tonsillectomy, performed against a backdrop of SDB, demonstrated improvements in behaviour, neurocognitive function, quality of life and vocal quality. Similar studies have demonstrated improvement in physical and emotional symptoms, as well as daytime functioning. ${ }^{[40-42]}$ In children with obstructive sleep apnoea (OSA), pulmonary hypertension was also shown to normalise on post-tonsillectomy echocardiography. Although most studies showed improvement in at least one outcome measure, these results are potentially misleading, as none of the studies was randomised. The CHAT trial (Childhood Adenotonsillectomy Trial $)^{[43]}$ published in 2013 was devised to address this shortcoming. A total of 464 children with obstructive sleep apnoea syndrome (OSAS), aged 5 - 9 years, were randomly assigned to either early adenotonsillectomy or watchful waiting. Outcome measures included general health, polysomnographic findings, behavioural and neurocognitive changes, assessed at baseline and 7 months after adenotonsillectomy. The study concluded that in children of school-going age with OSAS, surgery offered no improvement in attention or executive function. There was, however, improvement in behaviour, quality of life and polysomnographic findings following surgery, supporting early adenotonsillectomy in children with OSAS. This benefit was greater in obese children, although $33 \%$ of them had residual OSAS postoperatively. It should be noted that outcome measures showed improvement in the watchful waiting group too, but not to the same extent. Polysomnography, for example, improved in $79 \%$ of children undergoing surgery, and nearly half $(46 \%)$ of the children in the watchful waiting group. With few adverse events, the CHAT trial supported the safety of both surgery and watchful waiting, but emphasised the importance of close monitoring of the watchful waiting group. Watchful waiting was deemed a valid therapeutic option.

In addition, tonsillar disease is often outgrown, the tonsils contribute to the protective functioning of the immune system, and adeno- $/$ tonsillectomy is a procedure associated with significant morbidity ${ }^{[44]}$ and a mortality rate ranging from 1 in 16000 to 1 in $35000 .^{[45]}$ The risk and potential complications of adeno-/tonsillectomy are well documented and include the anaesthetic risk of laryngospasm, laryngeal oedema, aspiration, respiratory compromise, endotracheal tube ignition and cardiac arrest, as well as the intraoperative risk of blood loss, trauma to the teeth, tongue, pharynx, larynx and soft palate, lip, eye and mandible, and postoperative complications such as haemorrhage, delayed feeding and dehydration, nausea and vomiting, 
pain and otalgia, post-obstructive pulmonary oedema, velopharyngeal insufficiency, voice changes and nasopharyngeal stenosis. ${ }^{[4,46]}$ As such, the decision to offer patients an adeno-/tonsillectomy should not be a knee-jerk response, but a deliberated process, deemed to be in their best interests. Failure to meet the indications for adeno-/ tonsillectomy puts the patient at risk unnecessarily, with very little proven benefit.

\section{Social, geographical and family factors}

In the past, tonsillectomy was performed far more frequently in children of higher socioeconomic status. The social class association has, however, been reversed. According to the 2005 Chief Medical Officer's Report (UK), tonsillectomy is now more common in children from less affluent backgrounds. ${ }^{[6]}$ This is supported by the findings of international studies, which show that when access to healthcare is universally available, children of a lower socioeconomic status undergo tonsillectomy more frequently. ${ }^{[10,47]}$ In their study in India to assess the bacteriology of acute tonsillitis, Vijayashree et al. ${ }^{[48]}$ noted that $61 \%$ of cases came from a low-income group, $35 \%$ came from a middle-income group and only $4 \%$ came from a high-income group. The reasons cited for this preponderance of lower socioeconomic groups include poverty, malnutrition, unhygienic living conditions, illiteracy and poor access to healthcare. Like India, SA is a developing country, with an unemployment rate of $25 \%$ and a poverty level of $56.8 \% \cdot{ }^{[19]}$ It is therefore possible that acute tonsillitis is encountered more frequently in children of a lower socioeconomic standing and that the burden of disease (frequency and/or severity) in SA is greater than in the developed world. This could account for the high SA adeno-/tonsillectomy rate, except that most patients making use of the private healthcare sector are of a high socioeconomic standing, comparable with the developed world. To the authors' knowledge, no developing countries have reported an adeno-/tonsillectomy rate for comparison.

Physician-to-population ratio and patient proximity to a medical facility (geographical access barriers) have also been cited as potential factors contributing to variation in adeno-/tonsillectomy rates. ${ }^{[99]} \mathrm{We}$ found no such correlation in our study.

Tonsillectomy is often justified on the anecdotal opinion of parents whose children have undergone the procedure, claiming a dramatic improvement in their children's general health and behaviour. ${ }^{[16,50]}$ The perceived benefit of the procedure thus leads parents to request adeno-/tonsillectomy, as they believe surgery to be in the best interests of their children. These opinions are largely uninformed. However, parental preference or attempts at persuading doctors can interfere in the process of devising an appropriate management plan. Children with a parent or sibling who underwent tonsillectomy are also more likely to undergo the procedure. ${ }^{[11]}$ The behavioural and cognitive effects of OSAS are particularly worrisome to parents. ${ }^{[51]}$ As such, concerned parents might be more inclined to convince surgeons on the need for surgery. Often, parents' desire for cure and complete resolution of symptoms drives their insistence. Most children experience a degree of improvement in their SDB following tonsillectomy, but only $60-70 \%$ of patients experience complete resolution of their symptoms. Only $10-25 \%$ of obese children experience resolution of their symptoms. ${ }^{[52]}$ It is important for parents to be aware of this and not to harbour unrealistic expectations of improvement in symptoms. This might change parental attitudes towards surgery.

\section{Private practice funding model dictating clinical practice}

Fergusson and Horwood ${ }^{[53]}$ report that privately insured children under 7 years of age are more likely to undergo adeno-/tonsillectomy than their uninsured counterparts. It is conceivable that parents paying a premium for healthcare might feel entitled to dictate the nature of the management of their children and request surgical intervention. Similarly, doctors being reimbursed by patients might feel compelled to accede to their requests. Whether or not this occurs and is reasonable practice is debatable and beyond the scope of this article. SA private health insurers do not enforce evidence-based selection of patients for tonsillectomy. As such, this is a system open to over-servicing of patients.

\section{7. 'Soft' indications for adeno-/tonsillectomy}

Relative indications for surgery include recurrent episodes of tonsillitis requiring hospitalisation, peritonsillar abscess, febrile seizures, orthodontic concerns or malocclusion, tonsilliths, halitosis, family history of rheumatic heart disease or glomerulonephritis, and tonsillar asymmetry (to exclude malignancy on histological specimen). The evidence supporting these indications is limited and of a lower quality than the evidence on which established guidelines are based. In such instances, shared decision-making is promoted. Factors such as the number of days of school missed by a child as a result of tonsillitis, tonsil size, the number of antibiotic courses completed and recurrent ear infections, are often used to justify tonsillectomy, but are not included in any of the guidelines. ${ }^{[26]}$ The costs incurred as a result of frequent throat infections are substantial. These include the direct costs of consultation fees, transport and medication costs. Indirect costs include school and caregiver work absenteeism. Although cost and socioeconomic impact of disease are not included in the guidelines, the burden of disease is unequivocal, with an estimated 35 million days lost from school or work annually in the UK alone. ${ }^{[54]}$ However, in the UK, the cost of managing a child with recurrent sore throats over a 2-year period equated to about a third of the cost of managing the patient surgically, with the modest benefit in the tonsillectomy group of 3.5 episodes of sore throat fewer over the 2 -year period. ${ }^{[5]}$

In summary, with so many additional considerations complicating the decision-making process, it seems the need for adeno-/ tonsillectomy is open to interpretation and determined by the significance attached to each of the abovementioned factors by the healthcare provider involved.

\section{Study limitations}

Retrospectively reviewing medical aid data, as an indication of clinical practice, rendered us reliant on data provided by medical schemes and our audit subject to patient selection bias. The tonsillectomy rate was described only in the private healthcare sector, presumably therefore among children of a higher socioeconomic status. The ethnicity of our patients has also not been reported, precluding an assessment of tonsillectomy trends in different ethnic groups.

We have described the tonsillectomy rate in approximately $37 \%$ of the privately insured population (Discovery Health and Bonitas Medical Scheme), admittedly only a snapshot of the market. Collaboration between medical schemes would be required to report a more representative national private-sector tonsillectomy rate. It would also be interesting to determine the overall SA adeno-/ tonsillectomy rate, including the state sector, and to compare this rate with other developing countries. This would prove challenging, as no uniform reporting system or surgical registry in the SA state healthcare sector exists.

Indications for tonsillectomy are not recorded routinely by medical schemes and we cannot comment on the indications cited by surgeons to justify tonsillectomy in the SA private healthcare sector.

The authors believe that the findings of this study justify prospective analyses of tonsillectomy practice in the future. Assessing adherence to evidence-based guidelines and monitoring of tonsillectomy 
indications and rates are potential future avenues for research. It is also hoped that other developing countries will be encouraged to publish tonsillectomy rates.

\section{Conclusions}

The SA tonsillectomy rate is very high compared with international trends and also varies regionally within the country. The literature does not support an increased burden of disease as the reason behind this. Rather, it is differences in training and clinical practice of clinicians, as well as social and family factors, that have been implicated. It is hoped that this article generates awareness among those managing children with recurrent sore throats and SDB around current best evidence-based practice. Whether consideration for adeno-/tonsillectomy should be protocol/check-sheet driven or if surgery should be offered at the attending surgeons' discretion, is debatable. The authors, however, feel it would be a useful exercise to develop evidence-based, locally relevant indications for adeno-/ tonsillectomy to guide clinical practice in SA.

Acknowledgements. We acknowledge Discovery Health Medical Scheme and Bonitas Medical Fund for granting us access to their data. This research was not sponsored and the authors have no conflict of interest to declare.

1. Boss EF, Marsteller JA, Simon AE. Outpatient tonsillectomy in children: Demographic and geographic variation in the United States, 2006. J Pediatr 2012;160(5):814-819. DOI:10.1016/j. jpeds.2011.11.041

2. Owings MF, Kozak LJ. Ambulatory and inpatient procedures in the United States, 1996. Vital Health Stat 13 1998;139:1-119.

3. Cullen KA, Hall MJ, Golosinskiy A. National Center for Health Statistics (US). Ambulatory surgery in the United States, 2006. US Department of Health and Human Services, Centers for Disease Control and Prevention, National Center for Health Statistics, 2009. http://www.cdc.gov/nchs/data/nhsr/ nhsr011.pdf (accessed 11 November 2015).

4. Burton MJ, Glasziou PP, Chong LY, Venekamp RP. Tonsillectomy or adenotonsillectomy versus non-surgical treatment for chronic/recurrent acute tonsillitis. Cochrane Database Syst Rev 2014;(11):CD001802 DOI:10.1002/14651858.CD0011802.pub3

5. Wilson JA, Steen IN, Lock CA, et al. Tonsillectomy: A cost-effective option for childhood sore throat? Further analysis of a randomized controlled trial. Otolaryngol Head Neck Surg 2012;146(1):122-128. DOI:10.1177/0194599811422011

6. On the state of the public health: Annual report of the Chief Medical Officer $2005 \mathrm{http}: / /$ www.dh.gov uk/en/Publicationsandstatistics/Publications/AnnualReports/DH_4137366 (accessed 2 June 2015).

7. Rosenfeld RM, Green RP. Tonsillectomy and adenoidectomy: Changing trends. Ann Otol Rhinol Laryngol 1990;99(3 Pt 1):187-191.

8. Parker NP, Walner DL. Trends in the indications for pediatric tonsillectomy or adenotonsillectomy. Int J Pediatr Otorhinolaryngol 2011;75(2):282-285. DOI:10.1016/j.ijporl.2010.11.019

9. Rosefsky JB. Tonsillectomies and adenotonsillectomies - Will the debate never be over? Pediatrics 2003;112(1):205. DOI:10.1542/peds.112.1.205

10. Bisset AF, Russell D. Grommets, tonsillectomies, and deprivation in Scotland. BMJ 1994;308(6937):11291132. DOI:10.1136/bmj.308.6937.1129

11. Fried D. On tonsillectomy: Mom’s personal experience. Lancet 1995;346(8976):714. DOI:10.1016/ S0140-6736(95)9233-0

12. Cummins RO, Jarman B, White PM. Do general practitioners have different "referral thresholds"? Br Med J (Clin Res Ed) 1981;282(6269):1037-1039. DOI:10.1136/bmj.282.6269.1037

13. Fleming D, Crombie D, Cross K. An examination of practice referral rates in relation to practice structure, patient demography and case mix. Health Trends 1991;23(3):100-104.

14. Wilkin D, Smith AG. Variation in general practitioners' referral rates to consultants. J R Coll Gen Pract 1987;37(301):350-353.

15. Suleman M, Clark M, Goldacre M, Burton M. Exploring the variation in paediatric tonsillectomy rates between English regions: A 5-year NHS and independent sector data analysis. Clin Otolaryngol rates between English regions: A 5-year NHS and independ
2010;35(2):111-117. DOI:10.1111/j.1749-4486.2010.02086.x

16. Blair R, McKerrow W, Carter N, Fenton A. The Scottish tonsillectomy audit. J Laryngol Otol 1996;110(Suppl 20):1-25. DOI:10.1017/S0022215100136175

17. Volbracht E. Tonsillectomy in Germany: Marked regional variations in the most common inpatient operation performed on children and adolescents. Faktencheck Gesundheit Mandeloperation: Healthcare Fact Check 2013. Wiesbaden: German Federal Statistical Office, 2013.

18. Van den Akker E, Hoes A, Burton M, Schilder A. Large international differences in (adeno) tonsillectomy rates. Clin Otolaryngo Allied Sci 2004;29(2):161-164. DOI:10.1111/j.0307-7772.2004.00771.x

19. Statistics South Africa. General Household Survey, 2013. http://www.statssa.gov.za/publications/ P0318/P03182013.pdf (accessed 16 October 2015)

20. Goldstein NA, Stewart MG, Witsell DL, et al. Quality of life after tonsillectomy in children with recurrent tonsillitis. Otolaryngol Head Neck Surg 2008;138(1):S9-S16. DOI:10.1016/j.otohns.2006.12.029

21. Paradise JL, Bluestone $\mathrm{CD}$, Bachman RZ, et al. Efficacy of tonsillectomy for recurrent throat infection in severely affected children: Results of parallel randomized and nonrandomized clinical trials. N Engl J Med 1984;310(11):674-683. DOI:10.1056/nejm198403153101102
22. Van Staaij BK, Van den Akker EH, Rovers MM, Hordijk GJ, Hoes AW, Schilder AG. Effectiveness of adenotonsillectomy in children with mild symptoms of throat infections or adenotonsillar hypertrophy Open, randomised controlled trial. BMJ 2004;329(7467):651. DOI:10.1136/bmi.38210.827917.7c

23. Paradise JL, Bluestone CD, Colborn DK, Bernard BS, Rockette HE, Kurs-Lasky M. Tonsillectomy and adenotonsillectomy for recurrent throat infection in moderately affected children. Pediatrics 2002;110(1):7-15. DOI:10.1542/peds.110.1.7

24. Roos NP, Roos Jr LL, Henteleff PD. Elective surgical rates - do high rates mean lower standards? Tonsillectomy and adenoidectomy in Manitoba. N Engl J Med 1977;297(7):360-365.

25. Bloor MJ, Venters GA, Samphier ML. Geographical variation in the incidence of operations on the tonsils and adenoids. J Laryngol Otol 1978;92(10):883-895. DOI:10.1017/s0022215100086266

26. Capper R, Canter R. Is there agreement among general practitioners, paediatricians an otolaryngologists about the management of children with recurrent tonsillitis? Clin Otolaryngol Allied Sci 2001;26(5):371-378. DOI:10.1046/j.1365-2273.2001.00485.x

27. Tucker A. The current status of tonsillectomy - a survey of otolaryngologists. Clin Otolaryngol Allied Sci 1982; 7(6):367-372. DOI: $10.1111 / \mathrm{j} \cdot 1365-2273.1982$.tb01399 x

28. Darrow DH, Siemens C. Indications for tonsillectomy and adenoidectomy. Laryngoscope 2002;112(S100):6-10. DOI:10.1002/lary.5541121404

29. Buskens E, van Staaij B, van den Akker J, Hoes AW, Schilder AG. Adenotonsillectomy or watchful waiting in patients with mild to moderate symptoms of throat infections or adenotonsillar hypertrophy: A randomized comparison of costs and effects. Arch Otolaryngol Head Neck Surg 2007;133(11):1083A randomized comparison of costs and efret $10.1001 /$ archotol.133.11.1083

30. Marshall T, Anantharachagan A, Chan VG, Hoo SS, Yeo JC. How many tonsillectomies are evidence-based? J Clin Excell 2001;3(1):23-25. http://www.ingentaconnect.com/content/tandf jce/2001/00000003/00000001/art00005 (accessed 3 March 2016)

31. Brown P, Ryan R, Yung M, Browne J, Copley L, Cromwell D. The National Prospective Tonsillectomy Audit: Final report of an audit carried out in England and Northern Ireland between 2003 and 2004 London: Royal College of Surgeons of England, 2005. https://www.rcseng.ac.uk/surgeons/research/ surgical-research/docs/National\%20Prospective $\% 20$ Tonsillectomy\%20Audit\%20Final\%20Report\%20 2005.pdf (accessed 9 February 2016).

32. Archer S, Rosenfeld R, Mitchell R, Baugh R. Clinical practice guideline: Tonsillectomy in children Otolaryngol Head Neck Surg 2011;144(1 Suppl):S1-S30. DOI:10.1016/j.otohns.2010.06.616

33. Mitchell RB, Pereira KD, Friedman NR. Sleep-disordered breathing in children: Survey of current practice. Laryngoscope 2006;116(6):956-958. DOI:10.1097/01.mlg.0000216413.22408.fd

34. Woolford T, Ahmed A, Willatt D, Rothera M. Spontaneous resolution of tonsillitis in children on the waiting list for tonsillectomy. Clin Otolaryngol Allied Sci 2000;25(5):428-430. DOI:10.1046/j.1365-2273.2000.00402.x

35. Wood B, Wong Y, Theodoridis C. Paediatricians look at children awaiting adenotonsillectomy. Lancet 1972;300(7778):645-647. DOI:10.1016/s0140-6736(72)93028-0

36. Fox R, Temple M, Owens D, Short A, Tomkinson A. Does tonsillectomy lead to improved outcomes over and above the effect of time? A longitudinal study. J Laryngol Otol 2008;122(11):1197-1200. DOI:10.1017/s0022215107001557

37. Freeland AP, Curley JW. The consequences of delay in tonsil surgery. Otolaryngol Clin North Am 1987;20(2):405-408

38. Prim M, de Diego J, Larrauri M, Diaz C, Sastre N, Gavilan J. Spontaneous resolution of recurren tonsillitis in pediatric patients on the surgical waiting list. Int J Pediatr Otorhinolaryngol 2002;65(1):3538. DOI:10.1016/s0165-5876(02)00128-3

39. Garetz SL. Behavior, cognition, and quality of life after adenotonsillectomy for pediatric sleepdisordered breathing: Summary of the literature. Otolaryngol Head Neck Surg 2008;138(1):S19-S26. DOI:10.1016/j.otohns.2007.06.738

40. Mitchell RB, Kelly J. Behavior, neurocognition and quality-of-life in children with sleep-disordered breathing. Int J Pediatr Otorhinolaryngol 2006;70(3):395-406. DOI:10.1016/ji.jporl.2005.10.020

41. Flanary VA. Long-term effect of adenotonsillectomy on quality of life in pediatric patients. Flanary VA. Long-term effect of adenotonsillectomy on quality of life in

42. De Serres LM, Derkay C, Sie K, et al. Impact of adenotonsillectomy on quality of life in children with obstructive sleep disorders. Arch Otolaryngol Head Neck Surg 2002;128(5):489-496. DOI:10.1001/ archotol.128.5.489

43. Marcus CL, Moore RH, Rosen CL, et al. A randomized trial of adenotonsillectomy for childhood sleep apnea. N Engl J Med 2013;368(25):2366-2376. DOI:10.1056/nejmoa1215881

. Johnson LB, Elluru RG, Myer CM. Complications of adenotonsillectomy. Laryngoscope 2002;112(S100):35-36. DOI:10.1002/lary.5541121413

45. Pratt LW, Gallagher RA. Tonsillectomy and adenoidectomy: Incidence and mortality, 1968 - 1972 Otolaryngol Head Neck Surg 1979;87(2):159-166.

46. Acevedo JL, Shah RK, Brietzke SE. Systematic review of complications of tonsillotomy versu tonsillectomy. Otolaryngol Head Neck Surg 2012;146(6):871-879. DOI:10.1177/0194599812439017

7. Croxford R, Friedberg J, Coyte P. Socio-economic status and surgery in children: Myringotomies and tonsillectomies in Ontario, Canada, 1996 - 2000. Acta Paediatr 2004;93(9):1245-1250. DOI:10.1111/i.1651-2227.2004.tb02757.x

48. Vijayashree M, Viswanatha B, Sambamurthy B. Clinical and bacteriological study of acute tonsillitis. J Dental Vijayashree M, Viswanatha B, Sambamurthy B. Clinical and bacteriological study of acute tonsillitis.
Med Sci 2014;13(1):37-43. https://ndownloader.figshare.com/files/1841147 (accessed 3 April 2016).

49. Mayer ML, Beil HA, von Allmen D. Distance to care and relative supply among pediatric surgical subspecialties. J Pediatr Surg 2009;44(3):483-495. DOI:10.1016/j.jpedsurg.2008.08.015

50. Conlon B, Donnelly M, McShane D. Improvements in health and behaviour following childhood tonsillectomy: A parental perspective at 1 year. Int J Pediatr Otorhinolaryngol 1997;41(2):155-161 DOI:10.1016/s0165-5876(97)00073-6

51. Chervin RD, Ruzicka DL, Giordani BJ, et al. Sleep-disordered breathing, behavior, and cognition in children before and after adenotonsillectomy. Pediatrics 2006;117(4):e769-e778. DOI:10.1542/peds.2005-1837

52. Friedman $\mathrm{M}$, Wilson $\mathrm{M}$, Lin $\mathrm{H}$, Chang $\mathrm{H}$. Updated systematic review of tonsillectomy and adenoidectomy for treatment of pediatric obstructive sleep apnea/hypopnea syndrome. Otolaryngol Head Neck Surg 2009;140(6):800-808. DOI:10.1016/j.otohns.2009.01.043

53. Fergusson DM, Horwood LJ. Private medical insurance and elective surgery during early childhood. N Z Med J 1985;98(782):538-540.

54. ENT UK (British Association of Otorhinolaryngology - Head and Neck Surgery) Indications for tonsillectomy: Position paper. 2009. http://www.bapo.org.uk/tonsillectomy_position_papers_09.pdf (accessed 3 April 2016)

Accepted 9 September 2016 